\title{
DESENVOLVIMENTO HUMANO - REPENSANDO CONCEITOS NO ÂMBITO INTERDISCIPLINAR
}

\author{
HUMAN DEVELOPMENT - RETHINKING CONCEPTS IN THE SCOPE \\ OF INTERDISCIPLINARY \\ DESARROLLO HUMANO - REPENSANDO CONCEPTOS EN EL \\ ÁMBITO INTERDISCIPLINARIO
}

Eliana Perez Gonçalves de Moura ${ }^{1}$ Gislaine Cristina Pereira²

${ }^{1}$ Doutora em Educação pela PUC/RS. Docente do Programa de Pós-Graduação em Diversidade Cultural e Inclusão Social da Universidade FEEVALE - Nova Hamburgo - RS - Brasil. ${ }^{2}$ Doutoranda Diversidade Cultural e Inclusão Social pelo Programa de Pós-Graduação em Diversidade Cultural e Inclusão Social da Universidade FEEVALE - Nova Hamburgo - RS - Brasil.

Resumo: O estudo do desenvolvimento humano, diante da constante e complexa transformação nos domínios teórico-práticos interdisciplinares, vem sendo pensado de maneiras diversas. Apesar dos recursos financeiros continuarem sendo relevantes, o crescimento econômico deixa de ser primordial na composição deste conceito, sendo complementado pelo fator humano. O objetivo é apresentar um breve resgate compreensivo sobre desenvolvimento humano. Utiliza-se o método bibliográfico, com a busca por meio do descritor desenvolvimento humano, sendo direcionada para livros e periódicos científicos, publicados a partir de 1980, partindo do IDH/PNUD, para outras abordagens interdisciplinares. Percebese a importância de compreender o desenvolvimento humano para além dos aspectos econômicos, sem desconsiderar o IDH que contempla renda, saúde e educação. Conclui-se que a noção ampliada do termo destaca, além destes indicadores, os aspectos físico, cognitivo, psicossocial, histórico, cultural e principalmente subjetivo para a compreensão de desenvolvimento humano.

Palavra-chave: Desenvolvimento Humano; Interdisciplinaridade; Fator Humano.

\begin{abstract}
The study of human development, faced with the constant and complex transformations in the interdisciplinary theoretical-practical domains, has been thought of in different ways. Although financial resources continue to be relevant, economic growth ceases to be paramount in the composition of this concept, and is complemented by the human factor. The objective of this study is to present a brief comprehensive history of human development. The bibliographical method is used, searching on the term human development, and focusing on books and scientific journals published from 1980, starting from the HDI/PNUD, for other interdisciplinary approaches. The importance is perceived of understanding human development beyond economic aspects, without disregarding the HDI, which includes income, health and education. It is concluded that the expanded notion of the term highlights, beyond these indicators, the physical, cognitive, psychosocial, historical, cultural and especially subjective aspects for the understanding of human development.
\end{abstract}

Keywords: Human Development; Interdisciplinarity; Human Factor.

Resumen: El estudio del desarrollo humano, ante la constante y compleja transformación en los dominios teórico-prácticos interdisciplinarios, viene siendo pensado de maneras diversas. A pesar 
de que los recursos financieros siguen siendo relevantes, el crecimiento económico deja de ser primordial en la composición de este concepto, siendo complementado por el factor humano. El objetivo es presentar un breve rescate comprensivo sobre el desarrollo humano. Se utiliza el método bibliográfico, con la búsqueda a través del descriptor desarrollo humano, y está dirigido a libros y periódicos científicos publicados a partir de 1980, partiendo del IDH / PNUD, para otros abordajes interdisciplinarios. Se percibe la importancia de comprender el desarrollo humano más allá de los aspectos económicos, sin desconsiderar el IDH que contempla renta, salud y educación. Se concluye que la noción ampliada del término destaca además de estos indicadores los aspectos físico, cognitivo, psicosocial, histórico, cultural y principalmente subjetivo para la comprensión del desarrollo humano.

Palabras clave: Desarrollo humano; Interdisciplinariedad; Factor humano.

\section{INTRODUÇÃO}

A determinação conceitual do desenvolvimento, segundo Rossetti-Ferreira (2008), interliga-se diretamente à diversidade dos significados que emergem da articulação dos aspectos vinculados a uma multiplicidade de pessoas em interação em um mesmo contexto. Assim, o desenvolvimento humano representa, conforme Dessen e Costa Júnior (2008), uma constante reorganização inserida nos limites de determinado espaço-tempo que ocorre na efetivação de atitudes, percepções e interações com diferentes sujeitos. Ressalta-se, conforme os autores, que o desenvolvimento pode ser estimulado ou inibido conforme essas vivências em seu ambiente. No entanto, tais articulações e relações estão em contínua alteração, como consequência dos fatos e do próprio tempo.

Papalia (2006) enfatiza que, de modo geral, o desenvolvimento humano é compreendido como o estudo científico sobre as mudanças dos sujeitos e, ao mesmo tempo, sobre as características que permanecem regulares durante toda a vida. Complementando essa ideia, com base na visão ampliada do referido conceito, de acordo com Riquelme (2010), o cenário do desenvolvimento, na dimensão social, econômica, biológica, financeira, entre outras, ramificase em múltiplas categorias. No entanto, a maioria destas baseia-se em informações técnicas superficiais, às vezes simplificadas e artificiais. Neste sentido, ressalta-se que,

El simple crecimiento no basta. La riqueza mundial crece em términos absolutos, pero aumentan también las desigualdades. No sólo basta progresar desde el punto de vista económico y tecnológico; el desarrollo necessita ser ante todo humano, sostenible e integral. (RIQUELME, 2010, p. 09).

Diante da constante e complexa transformação nos domínios teórico-práticos interdisciplinares, visualiza-se, segundo Dessen e Guedea (2005), uma nova proposta para o estudo do desenvolvimento, mais especificamente em relação ao desenvolvimento humano gerando significativo impacto no contexto científico. De acordo com as autoras, a continuidade e a mudança fazem parte de um conjunto diversificado de aspectos do sujeito. Por isso, Papalia, Olds e Feldman (2006) destacam que o estudo dessa temática se torna extremamente complexo, voltando-se para algumas variáveis, como desenvolvimento biológico, cognitivo, psicossocial, etc. Facci (2004, p. 65) reitera essa compreensão afirmando que "o desenvolvimento humano foi organizado em estágios distintos evolutivos: orgânicos, motores, cognitivos, afetivos, sexuais, morais, sociais, históricos e culturais". 
Em contrapartida, esse cenário desencadeou uma profunda crise de paradigmas, tendo em vista as dimensões multivariadas do comportamento. É notório que essa crise acarreta "o problema crucial de elaborar formas de descrição de sistemas, teorias" (BORGES, 1987, p. 13). Assim, o estudo do desenvolvimento humano exige, também, conforme Dessen e Costa Júnior (2008, p. 12), "a adoção de modelos sistêmicos e a implementação de pesquisas interdisciplinares e multicêntricas". Essa perspectiva desperta atenção para

[...] as possíveis limitações na categorização e na descrição dos fenômenos e sobre a relação entre metodologias e seus objetos de investigação, favorecendo uma visão dialógica, integrada, pluralística e complexa do desenvolvimento humano. (DESSEN; COSTA JÚNIOR, 2008, p. 12).

As múltiplas e diversificadas formas de se compreender o desenvolvimento humano tornam imprescindível o investimento em novas pesquisas que aprimorem conceitualmente esta temática. Assim, considerando o sujeito como em constante evolução por meio de relações interpessoais e vivências com o meio, no presente texto se pretende apresentar um breve resgate reflexivo conceitual sobre o desenvolvimento humano. Utiliza-se o método bibliográfico, com a busca por meio do próprio termo como descritor, sendo direcionada para livros e periódicos científicos, publicados a partir de 1980, partindo do IDH / PNUD, para outras abordagens interdisciplinares.

\section{Desenvolvimento Humano: Reflexões Conceituais}

Sob o ponto de vista evolutivo, a questão do desenvolvimento humano sempre foi motivo de problematização. No entanto, o interesse em pesquisas formais sobre o assunto é relativamente novo. No século XXI, o desenvolvimento integral configurou-se como uma nova questão social. As teorias que abordam o tema tentam interpretar o progresso dos países focando no "equilíbrio entre bem-estar material e a justiça social" (RIQUELME, 2010, p. 08).

Tomando-se por base o Programa das Nações Unidas para o Desenvolvimento Humano (PNUD), o desenvolvimento emerge como um "processo de ampliação das liberdades das pessoas, com relação às suas capacidades e as oportunidades a seu dispor, para que elas possam escolher a vida que desejam ter" (PNUD, 2015, s/p). Essa perspectiva engloba fatores econômicos, ambientais, políticos e sociais, considerados relevantes na efetivação de muitas possibilidades para as pessoas, acompanhadas da existência de um contexto que promova o exercício pleno de seu potencial.

Para o PNUD, apesar da renda e dos recursos financeiros continuarem sendo relevantes, o crescimento econômico deixa de ser primordial e passa à condição de mediador, sendo superado pelo fator humano. Esta concepção reforça a ideia da renda e dos recursos concebidos como meios do desenvolvimento, não mais se configurando seu próprio fim. $\mathrm{O}$ PNUD desenvolveu o Índice de Desenvolvimento Humano (IDH) como alternativa ao indicador econômico baseado no Produto Interno Bruto (PIB), que durante muitos anos foi a única medida do desenvolvimento. Trata-se de uma ampliação conceitual que popularizou a abordagem do desenvolvimento humano (PNUD, 2015). 
Essa mudança de foco é fundamental pois, na atualidade, o crescimento econômico da população não pode ser diretamente vinculado à qualidade de vida, porque, muito frequentemente, o aumento no crescimento econômico traz como consequência o reforço e a ampliação das desigualdades (PNUD, 2015). Assim, importa transformar o crescimento financeiro em conquistas reais para o coletivo, as quais podem ser entendidas como o próprio desenvolvimento, que pode ser reconhecido por meio de alguns aspectos importantes:

[...] crianças mais saudáveis; educação universal e de qualidade; ampliação da participação política dos cidadãos; preservação ambiental; equilíbrio de renda (custo de vida - potencial de compra) e das oportunidades entre todas as pessoas; maior liberdade de expressão, entre outras. (PNUD, 2015, s/p).

Ressalta-se que, em relação à expansão das liberdades das pessoas, o Programa das Nações Unidas para o Desenvolvimento Humano (PNUD) defende a utilização do Índice de Desenvolvimento Humano (IDH) como instrumento de avaliação. O índice amplia a compreensão defendida pelo PIB, reunindo três dos requisitos mais importantes para essa conquista, sendo eles a saúde, avaliada com base na oportunidade de se levar uma vida longa e saudável; a educação, no sentido de que todos devem ter acesso ao conhecimento; e a renda, concebida como a possibilidade de desfrutar de um padrão de vida digno.

Reforçando a compreensão de cada categoria de avaliação do IDH, destaca-se que saúde é entendida como ampliação das oportunidades disponíveis às pessoas para evitar a morte prematura, e que lhes seja garantido um ambiente saudável, com acesso à saúde de qualidade, para que possam atingir o padrão mais elevado possível de saúde física e mental. Em relação ao aspecto educacional, parte-se da concepção de que a educação é essencial para o exercício das liberdades individuais, da autonomia e da autoestima. E, ao mesmo tempo, este indicador é um dos principais pilares para expansão das habilidades das pessoas, para que elas possam decidir sobre seu futuro, reforçando a confiança, conferindo dignidade e ampliando os horizontes e as perspectivas de vida. Por fim, a renda representa o acesso às necessidades básicas como água, comida e abrigo, mas também para tornar possível a oportunidade de transcender essas necessidades rumo a uma vida de escolhas genuínas e exercícios de liberdades. Sua ausência pode limitar as oportunidades de vida.

Contudo, Feres e Mancero (2001) afirmam que, apesar da sua ampla abrangência, são várias as críticas direcionadas ao IDH, geralmente focadas nos aspectos metodológicos, mais especificamente, em "variables consideradas, ponderadores utilizados, irrelevancia de resultados, etc." (FERES; MANCERO, 2001, p. 335). Depois de tantos anos de existência do IDH, a sua principal contribuição tem sido ressaltar a concepção de que "el crecimiento económico es un medio para servir a fines humanos y no un fin em sí mismo" (p.358).

A origem conceitual do termo foi a ciência econômica tendo por intuito obter o índice desenvolvimento econômico (SANTANA, 2011). No entanto, essa visão reduzida possibilitou a incorporação de outras disciplinas à sua compreensão, acompanhando a tendência de atribuir um viés mais humano ao conceito.

Atualmente os cientistas enfatizam que o desenvolvimento ocorre por toda a vida. Papalia, Olds e Feldman (2006) definem esse processo como "Desenvolvimento do Ciclo Vital", apontando como princípios fundamentais a existência de determinações estruturantes básicas, 
sendo elas "o desenvolvimento é vitalício; depende de história e contexto e é multidimensional e multidirecional" (PAPALIA; OLDS; FELDMAN, 2006, p.48-49).

\section{Teorias Deterministas do Desenvolvimento Humano}

As teorias deterministas do desenvolvimento apresentadas a seguir indicam duas concepções contraditórias, mas complementares sobre desenvolvimento humano. $\mathrm{O}$ conhecimento de ambas contribui para a análise reflexiva conceitual do termo, sendo que de um lado está a Visão Biológica do Desenvolvimento Humano e de outro a Visão Ambientalista (ou behaviorista) sobre o mesmo.

De acordo com Ré (2011), Rogoff (2005) e Papalia, Olds e Feldman (2006), durante todo o ciclo de vida humana ocorrem processos considerados base de desenvolvimento que se relacionam intimamente no sentido de completude, como o crescimento e a maturação. 0 desenvolvimento humano é visto como resultado da "interação entre as características biológicas individuais (crescimento e maturação) com o meio ambiente ao qual o sujeito é exposto durante a vida" (RÉ, 2011, p. 56). No entanto, Nascimento e Dantas (2004) registram que, por muito tempo a teoria inatista, ou biológica, foi hegemônica, afirmando o determinismo biológico diante das demais concepções. E ainda que hoje essa teoria já tenha sido revisada, não mais sendo considerada a única fonte explicativa, o seu estudo continua sendo de relevância.

Essa teoria defende o potencial hereditário (ou intrínseco) do indivíduo, anulando qualquer influência do meio no seu desenvolvimento. Seria o organismo, com seus "processos de crescimento físico e maturacional que determinaria incondicionalmente o processo de desenvolvimento" (NASCIMENTO; DANTAS, 2004, p. 8). Nessa perspectiva, não há diferenciação entre o desenvolvimento humano e o desenvolvimento dos demais animais, já que ele é expresso por meio da concepção puramente biológica, determinado pelo material genético de cada pessoa, que se transforma em decorrência do estado maturacional, das forças internas apresentadas. Percebe-se, conforme os autores citados, "a redução do desenvolvimento humano a um processo puramente quantitativo" (p. 9). Isso remete, a entender o ser humano como reduzido ao biológico, tendo suas características já determinadas no momento do nascimento, as quais são apenas afloradas ao longo da vida. O sujeito estaria fadado a apresentar ou não as condições (aptidões) para aprender, de acordo com as características hereditárias que possui (GOMES, 2002).

Dentro da visão biológica do desenvolvimento humano, vale ainda destacar o registro crítico feito por Nascimento e Dantas (2004, p. 9) sobre a referida concepção:

[...] torna-se impossível a captação e explicação de todas as mudanças e transformações verificadas na conduta da criança. [...]. Não há espaço no interior desta concepção, para possíveis análises da influência do meio ou do social no desenvolvimento humano.

E para romper com esse paradigma, Nascimento e Dantas (2004) ressaltam que a própria investigação científica precisou criar novas formas de visualizar o tema buscando diferentes perspectivas teóricas. Dentre outras, Gomes (2002) destaca a concepção do determinismo do meio na teoria empirista/ambientalista ou behaviorista. 
Autores destaques desta teoria, Pavlov e Skinner, investiram no deslocamento explicativo sobre a formação do ser humano, do organismo para o meio. Ao contrário da teoria inatista, esta teoria defende que a experiência com o meio físico e social ao qual o sujeito está inserido é que gera todo seu conhecimento e suas transformações comportamentais (GOMES, 2002). Defende-se que o meio é determinante do desenvolvimento do homem, de forma plena e exclusiva. O sujeito passa a ser concebido apenas como uma cópia das condições externas (GOMES, 2004).

Ocorre, então, uma contradição entre concepções. Se na teoria inatista nega-se totalmente a influência do meio, na teoria behaviorista, o que é negado é o determinismo biológico da evolução humana. As teorias deterministas do desenvolvimento humano, tanto a focada na visão inatista como a ambientalista ou behaviorista, são incapazes de explicar em sua totalidade a referida temática, sendo consideradas extremamente reducionistas. Contudo, uma terceira teoria emerge no centro dos debates a respeito do desenvolvimento humano, buscando suprir as lacunas apresentadas pelas visões anteriores: o interacionismo (NASCIMENTO; DANTAS, 2004).

\section{TEORIA INTERACIONISTA DO DESENVOLVIMENTO HUMANO}

Na busca pela eliminação da dicotomia e unilateralismo entre o biológico e o ambiental, surge a concepção interacionista defendendo que o desenvolvimento resulta de um processo complexo que se estabelece diante da interação entre o homem e o meio no qual está inserido. Dessa forma amplia-se o reconhecimento da possibilidade de o meio social influenciar profundamente o processo de desenvolvimento humano. No entanto, essa concepção ainda não consegue explicar tudo o que envolve o termo, pois

[...] não é apenas no reconhecimento da existência de um social que encontramos a chave para a explicação dos processos de desenvolvimento e formação humana, mas o encontramos sim no modo como esse social é considerado e toma parte para a explicação daqueles processos. (NASCIMENTO; DANTAS, 2004, p. 12).

Desde o início da vida, a construção das relações apresenta-se como principal ponto de partida compreendidas como ações partilhadas e interdependentes. A determinação conceitual do desenvolvimento interliga-se diretamente à diversidade dos significados que emergem da articulação de pessoas em um determinado período. Ou seja, essa articulação está em contínua alteração, em virtude dos fatos e do próprio tempo. Corroboram com essa compreensão os autores Dessen e Costa Júnior (2008), quando afirmam que:

O desenvolvimento humano representa uma reorganização contínua dentro da unidade tempo-espaço, que opera no nível das ações, percepções, atividades e interações do indivíduo com seu mundo, sendo estimulado ou inibido por meio das interações com diferentes participantes do ambiente da pessoa (DESSEN; COSTA JÚNIOR, 2008, p. 11).

O desenvolvimento humano vincula-se à necessidade de entendimento de um amplo conjunto de aspectos envolvidos na concepção de sujeito, suas questões biológicas, físicas, psíquicas e o modo como interage na comunidade. Ao mesmo tempo, atualmente não há 
como encontrar uma única explicação do termo sem considerar a cultura, a historicidade e os fatores ambientais que atravessam o cotidiano do sujeito. Essa nova abordagem reúne autores que buscam compreender os diferentes aspectos envolvidos pela temática. Retomando Dessen e Costa Júnior (2008), a atualidade apresenta um contexto de ruptura de paradigmas, fortalecendo o despertar da relevância do contexto social na investigação dos fenômenos.

Esse novo formato de análise de sujeito e de seu desenvolvimento enfatiza que a maneira como o sujeito elabora a si mesmo está intimamente vinculada à maneira como ele elabora o "outro" e vice-versa. Assim, as relações sociais passam a constituir base fundamental para a formação e desenvolvimento das pessoas (DESSEN; COSTA JÚNIOR, 2008).

Nesse sentido a história interacional, ou seja, a maneira como as pessoas interagem no tempo/espaço entre si, ganha significativa relevância por construir as características pessoais do sujeito, ao mesmo tempo em que geram sentido nas relações contextualizadas. Ao se reportar ao "outro" como construtor conjunto da concepção de si mesmo e vice-versa, partese do entendimento de que o processo de construção das identidades pessoais e grupais se elabora em decorrência do que Rossetti-Ferreira (2008) define como sendo o jogo de interação entre o sujeito e o outro.

Assim, diante da complexidade que surge na atualidade acerca da concepção ampla do desenvolvimento humano, faz-se necessário e urgente o fortalecimento de uma postura aberta à diversidade, direcionada às "múltiplas perspectivas possíveis, às várias vozes que ecoam. Esta compreensão sempre esteve vinculada às ciências humanas e sociais mas, na atualidade transborda para as áreas exatas e biológicas". O objetivo é a desconstrução e a superação das pseudopolaridades entre "biológico/natural e social - universalidade e singularidade permanência e ruptura - determinismo e indeterminismo - emoção e cognição - corpo e mente - interno e externo" (ROSSETTI-FERREIRA, 2008, p.24). Portanto, conforme a mesma autora, o movimento de aceitação da própria contradição, das concepções opostas ou do próprio conflito como inerentes ao processo de desenvolvimento promove a integração das polaridades distintas, entendendo-as como constituintes fundamentais do próprio processo. Aqui a pessoa passa a ser compreendida como múltipla, porque

[...] são múltiplas as vozes que compõem o mundo social, os espaços e as posições que vai ocupando nas práticas discursivas. Essa multiplicidade de vozes e posições que dialogam entre si submetem a pessoa, mas, ao mesmo tempo, preservam a abertura para a inovação e para a construção de novos posicionamentos e processos de significação acerca do mundo, do outro e de si mesma. (ROSSETTI-FERREIRA, 2008, p. 23).

O somatório dessas diferentes visões do desenvolvimento permite o despertar do protagonismo do sujeito, que passa a ter a possibilidade de conquistar a função de "agende de mudança e de transformação da sua própria história" (SIFUENTES; DESSEN; OLIVEIRA, 2007, p.379). Fato que também é resgatado pela PNUD como parte do que se compreende ser a definição ampliada do desenvolvimento humano. Por isso defende-se que o conceito implica a necessidade de entendimento de um amplo conjunto de aspectos fundamentais, dentre eles as questões biológicas, físicas, psíquicas e o modo como o sujeito interage na comunidade. Atualmente não há como abordar a noção de desenvolvimento humano sem considerar a 
cultura, a historicidade, o social e os fatores ambientais que atravessam o cotidiano do sujeito (DESSEN; COSTA JÚNIOR, 2008).

Esse novo formato de análise da referida temática enfatiza que a maneira como o sujeito elabora a si mesmo está intimamente vinculada à maneira como elabora o "outro" e vice-versa. Ou seja, a construção de si, a elaboração da compreensão de seu mundo ocorre a partir da relação com o "outro", que também se pode nomear como inter-relações. Conforme Sifuentes, Dassem e Oliveira (2007, p. 379), "todos os membros de uma determinada cultura participam ativamente da sua construção, influenciando e sendo influenciados, em uma dinâmica mútua, que possibilita a emergência do novo". As relações sociais passam a constituir, por meio dessas novas bases conceituais, o pilar fundamental para a formação e o desenvolvimento das pessoas porque, por meio delas "aprendemos e nos desenvolvemos, criamos novas formas de agir no mundo ampliando nossas ferramentas de atuação neste contexto cultural complexo que nos recebeu, durante todo o ciclo vital" (RABELLO; PASSOS, 2015, p. 1).

Dessen e Guedea (2005) indicam como caminho para reestruturação conceitual do desenvolvimento humano a criação de estratégias diversificadas capazes de envolver múltiplos fatores no intuito de captar a complexidade que o termo exige, focando o todo e não apenas algumas de suas partes. Primeiramente, o foco de atenção deve estar não somente no sujeito, mas nas suas redes sociais, ressaltando a complexidade dialética envolvida nessas relações. $\mathrm{E}$ se destaca, também, a vinculação da psicologia do desenvolvimento, juntamente com muitas outras concepções teóricas disciplinares, reforçando a multiplicidade conceitual da temática.

Não se pode deixar de mencionar, no entanto, a importância dos aspectos subjetivos para o processo de construção da noção de desenvolvimento humano. Ao mesmo tempo, conforme Dessen e Costa Júnior (2008), os aspectos subjetivos não devem ser analisados por meio da descrição limitada das partes do processo. Ou seja, o todo adquire relevância plena e características peculiares tendo em vista o entrelaçamento dos níveis e subníveis presentes em um determinado período de tempo e espaço. Assim, a compreensão conceitual do desenvolvimento humano ultrapassa os limites dos índices estatísticos apresentados pelo PIB e IDH, enfatizando aspectos que, muitas vezes, são difíceis de mensurar porque não se reduzem a indicadores. Trata-se de dimensões subjetivas, que contribuem significativamente para a compreensão de desenvolvimento humano.

\section{O Desenvolvimento Humano e a Psicologia}

De acordo com Bellini-Leite et al. (2010), o século XX foi marcado por inúmeras transformações em diversos âmbitos, principalmente no que diz respeito à criação de novos paradigmas. Mais especificamente na década de 60, também a psicologia obteve mudanças, destacando-se aqui a chamada Terceira Força, o Movimento Humanista.

A ênfase principal da Psicologia Humanista estava no "poder do homem, suas aspirações positivas, a experiência consciente, o livre-arbítrio, a utilização do potencial humano e a noção de integridade da natureza humana" (BELLINI-LEITE et al., 2010, p. 310). 
Mesmo diante da existência de correntes profundamente fortalecidas da psicologia nasce o Movimento Humanista.

Dentre os representantes desse movimento, Abraham Maslow e Carl Rogers recebem destaque. O primeiro, reconhecido como pai da psicologia humanista, focou sua teoria na compreensão e no destaque do potencial do ser humano para grandes realizações, entendendo este como uma tendência inata à autorrealização (SCHULTZ; SCHULTZ, 2005). Para melhor representar essa ideia, Maslow criou uma pirâmide nomeada "Hierarquia das Necessidades", a qual sugere que, para conquistar a autorrealização, o sujeito deve subir todos os seus degraus. Somente após a conquista de cada um dos níveis é possível evoluir para os demais. Maslow acredita que:

As pessoas auto-realizadas tendem a ter comportamentos como plena aceitação de sua natureza, simplicidade e naturalidade, empatia e afeição pela humanidade, atitude de criatividade, interesse social, percepção objetiva da realidade, resistência ao conformismo, caráter democrático, etc. (BELLINI-LEITE et al., 2010, p. 311).

O segundo representante do Movimento Humanista é Carl Rogers. Seu foco é defender a maneira como o sujeito percebe a realidade e não a realidade verdadeira. Entende-se que o subjetivo do ser humano é digno de todo o respeito; e para se compreender o comportamento, é necessário entender tanto a noção subjetiva da pessoa como do contexto em que ela vive. Rogers, semelhante a Maslow, defende que o ser humano tem a tendência a buscar o máximo de seu potencial, o que lhe dirige ao nível mais alto da humanização. O que poderia desviar essa conquista seriam os fatores ambientais.

Ainda que a Psicologia Humanista não tenha se fundado como escola de pensamento, a partir dos anos 90, um movimento com propostas de humanização passa a ganhar imensa notoriedade e reconhecimento: a chamada Psicologia Positiva. Tendo como seu principal defensor Martin Seligman, esta teoria defende métodos, técnicas e objetivos que visam desenvolver uma ciência com foco no lado positivo do ser humano (SCHULTZ; SCHULTZ, 2005). Ela enfatiza as experiências positivas vivenciadas tanto no presente quanto no passado envolvendo bem-estar e satisfação, alegria, felicidade -, quanto no futuro, abordando otimismo, esperança e fé. É possível ainda, nessa teoria, uma abordagem em âmbito individual focando na capacidade de amar, no desempenho, na coragem, no relacionamento interpessoal, no perdão e na sabedoria. E no âmbito coletivo tratando de "virtudes civilizadas, e instituições que movem os indivíduos para melhor cidadania, responsabilidade, altruísmo, moderação, tolerância e ética" (BELLINI-LEITE et al., 2010, p.312).

Na concepção da Psicologia Positiva, o desenvolvimento se configura a partir da transformação do sujeito de forma ampliada, não sendo reconhecida como mudança superficial. Isso porque a demonstração efetiva do mesmo determina que "uma mudança produzida nas concepções e/ou atividades da pessoa foi transferida para outros ambientes e outros momentos" (BROFENBRENNER, 1996, p. 28).

A interação social, de acordo com Paludo e Koller (2007), recebe grande relevância nessa perspectiva, pois o simples fato de estar convivendo pressupõe a mutualidade de oportunidade de desenvolvimento. Ou seja, "sempre que uma pessoa em um ambiente 
presta atenção às atividades de outra pessoa, ou delas participa, existe uma relação" (BROFENBRENNER, 1996, p.46).

Para a Psicologia Positiva, segundo Passarelli e Silva (2007), o bem-estar tem grande relevância, sendo um aspecto que oportuniza ao sujeito visualizar a si mesmo e demais pessoas permitindo aprimorar a satisfação em estar vivenciando o cotidiano. De acordo com os autores, já existem pesquisas que demonstram forte relação com o bem-estar e maior nível de felicidade nas relações sociais. Aqui, o desenvolvimento humano aparece permeado por aspectos qualitativos, como bem-estar, qualidade de vida e a própria convivência social, sendo estes importantes na análise conjunta dos demais - já referidos neste texto - para a compreensão ampliada do conceito.

Assim, compreende-se o desenvolvimento humano como o processo por meio do qual a pessoa que se desenvolve adquire uma concepção mais ampliada, diferenciada e válida do meio ambiente ecológico. Ao mesmo tempo, torna-se mais motivada e mais capaz de se envolver em atividades que revelam suas propriedades, sustentam ou reestruturam aquele ambiente em níveis de complexidade semelhante ou maior de forma e conteúdo (POLONIA; DESSEN; SILVA, 2005, p. 73).

\section{Considerações Finais}

O desenvolvimento humano vem sendo foco de estudos há muito tempo e sua compreensão conceitual vem apresentando uma evolução significativa. $O$ Índice de Desenvolvimento Humano (IDH) é um marco relevante no que tange a essa busca conceitual, pois amplia os indicadores econômicos existentes, como a renda, incorporando também índices relacionados à saúde e à educação. Esse conjunto de aspectos passou a ser base de avaliação do desenvolvimento humano no mundo todo. Apesar da origem econômica dessa discussão, outras disciplinas aderiram ampliando as possibilidades interpretativas, marcando a introdução de um viés mais humano ao conceito.

No entanto, o conceito ainda não atingiu o limite de sua representatividade, sendo alvo de novas abordagens interpretativas que ganham sentido na análise ampliada do termo, as quais se agregam complementarmente às concepções já existentes, especialmente os aspectos subjetivos, cuja característica, de difícil mensuração, não é passível de ser avaliada pelos indicadores já existentes. Além desse aspecto, que se agregou às discussões conceituais sobre desenvolvimento humano, também passaram a fazer parte da discussão as inter-relações que ocorrem no transcorrer da vida, assim como a qualidade de vida e o bem-estar. E os aspectos culturais e históricos também ganham força e influência para o entendimento da temática, direcionando-o para o âmbito coletivo, incorporando noções de cidadania, responsabilidade e ética. Assim, percebese a importância de considerar combinadamente os aspectos físico, cognitivo, psicossocial, econômico e cultural para a proposição de uma noção ampliada do termo.

A giz de encerramento, sugere-se o desenvolvimento de novos estudos que agreguem aos indicadores já existentes outros olhares e formas de concepção sobre o desenvolvimento humano, tendo como base os conceitos defendidos pela PNUD. É preciso abordar o potencial 
humano como elemento decisivo para o desenvolvimento, abrindo novas possibilidades de discussão. Aqui, destacam-se questões interdisciplinares, as quais devem ser capazes de resgatar diferentes saberes que contribuam para a compreensão ampliada do referido conceito, já que a interdisciplinaridade envolve questões promotoras do desenvolvimento humano, tais como diálogo, alteridade, criatividade, reciprocidade. Estes aspectos valorizam o indivíduo como ele é e o convidam a colocar sua rica singularidade à disposição do outro.

\section{REFERÊNCIAS}

BELLINI-LEITE, S.; HONÓRIO, T.; FARIA, C.; SANTOS, F. Humanização da Psicologia e a aplicação da Psicologia Positiva. CES Revista, Juiz de Fora, v. 24, 2010.

BORGES, M. Psicologia do Desenvolvimento. Jornal de Psicologia, Porto, 1987.

BRONFENBRENNER, U. A ecologia do desenvolvimento humano: experimentos naturais e planejados. Porto Alegre: Artes Médicas, 1996.

DESSEN, M. A.; COSTA JÚNIOR, A. A Ciência do Desenvolvimento Humano: tendências atuais e perspectivas futuras. Porto Alegre: ARTMED, 2008.

DESSEN, M. A.; GUEDEA, M. T. A Ciência do Desenvolvimento Humano: Ajustando o foco de análise. Paidéia, 2005, 15(30), 11-20.

FACCI, M.G. A periodização do desenvolvimento psicológico individual na perspectiva de Leontiev, Elkonin e Vygotski. Caderno CEDES, Campinas, vol. 24, n. 62, p. 64-81, abril 2004.

FERES, J. C.; MANCERO, X. A Medición del Desarrollo Humano: Elementos de um debate. CEPAL (Comisión Económica para América Latina y el Caribe), 2001, p. 333-365.

GOMES, M. Relações entre desenvolvimento e aprendizagem, consequência na sala de aula. Revista Presença Pedagógica, Belo Horizonte, v. 8, n. 45, p.37 - 49, 2002.

GOMES, M. Construindo relações de inclusão/exclusão na sala de aula de química: histórias sociais e singulares. Tese (Doutorado em educação). Faculdade de Educação/UFMG, 2004.

NASCIMENTO, C.; DANTAS, L.E. A psicologia histórico-cultural e o desenvolvimento infantil: reflexões a partir da e para a prática da educação infantil. Monografia. Universidade de São Paulo (USP) Escola de Educação Física e Esporte. São Paulo, 2004.

PALUDO, S.; KOLLER, S. Psicologia Positiva: uma nova abordagem para antigas questões. Revista Paidéia, 17(36), 9-20, 2007.

PAPALIA, D.; OLDS S.; FELDMAN, R. Desenvolvimento Humano. 8. ed. Artmed, 2006.

PASSARELLI, P. M.; SILVA, J. A. Psicologia positiva e o Estudo do Bem-Estar Subjetivo. Revista Estudos de Psicologia. Campinas 24(4) 513-517, Out-Dez, 2007.

PNUD. Programa das Nações Unidas para o Desenvolvimento Humano. Disponível em: www.pnud.org. br. Acessado em: 20.06.2015.

POLONIA, A.; DESSEN, M.; SILVA, N. O modelo bioecológico de Brofenbrenner: contribuições para o desenvolvimento humano. Dessen, M.; Costa Júnior, A. (Orgs.) A ciência do desenvolvimento humano: tendências atuais e perspectivas futuras. Porto Alegre: ArtMed, 2005, 71-89. 
RABELLO, E.; PASSOS, J. Vygotski e o Desenvolvimento Humano. Fundação José Silveira. Salvador, Bahia. Disponível em: www.fjs.org.br. Acessado em: 28.01.2015.

RÉ, A. H. N. Crescimento, maturação e desenvolvimento na infância e adolescência: Implicações para o esporte. Revista Motricidade FTCD/CIDESD. 2011, vol. 7, n. 3, pp. 55-67

RIQUELME, S. La política social ante el desarrollo humano sostenible. Propuestas de renovación teórica. Observatório Iberoamericano del Desarrollo Local y la Economía Social. Rev. Acad. Universidad de Málaga. Año 04, n. 08, junio de 2010.

ROGOFF, B. A Natureza Cultural do Desenvolvimento Humano. Artmed, Porto Alegre, 2005.

ROSSETI-FERREIRA, M. C. Rede de Significações: alguns conceitos básicos. In: ROSSETI-FERREIRA, M. C. et al. (Orgs.) Rede de Significações e o Estudo do Desenvolvimento Humano. Porto Alegre: Artmed, 2004, p. 23-34.

SANTANA, M. C. Derechos Humanos y Desarrollo Humano em México. Revista Latinoamericana de Derechos Humanos. Vol. 22(2): 185, julio-diciembre, 2011.

SCHULTZ, D. P.; SCHULTZ S. E. História da psicologia moderna. 8. ed. São Paulo: Thomson, 2005.

SIFUENTES, T.; DESSEN, M.; OLIVEIRA, M. Desenvolvimento Humano: Desafios para a compreensão das trajetórias probabilísticas. Revista Psicologia: Teoria e Pesquisa, Brasília, Out-Dez 2007, vol. 23, n. 04, p. 379-386.

Artigo recebido em: 24/02/2017

Aprovado em: 25/07/2017

\section{CONTATO PARA CORRESPONDÊNCIA:}

Gislaine Cristina Pereira. E-mail: psigislaine@gmail.com 